\title{
Differential Impact of an Executive-Function and a Social Cognition Training on Preschoolers with Externalizing Behavior Problems
}

\author{
Marine Houssa, Alexandra Volckaert, Nathalie Nader-Grosbois, Marie-Pascale Noël \\ Psychological Sciences Research Institute, Université catholique de Louvain, Louvain-La-Neuve, Belgium \\ Email: marine.houssa@uclouvain.be
}

How to cite this paper: Houssa, M., Volckaert, A., Nader-Grosbois, N. and Noël, M.-P. (2017) Differential Impact of an Executive-Function and a Social Cognition Training on Preschoolers with Externalizing Behavior Problems. Journal of Behavioral and Brain Science, 7, 598-620.

https://doi.org/10.4236/jbbs.2017.712042

Received: June 28, 2017

Accepted: November 20, 2017

Published: November 23, 2017

Copyright $\odot 2017$ by authors and Scientific Research Publishing Inc. This work is licensed under the Creative Commons Attribution International License (CC BY 4.0).

http://creativecommons.org/licenses/by/4.0/ Open Access

\begin{abstract}
In preschoolers, externalizing behavior problems are a primary cause of consultation. It is known that externalizing behavior (EB) could result from individual and environmental risk factors. Individual risk factors included notably social cognition (SC) and executive functions (EF). A high level of EB has usually been related to dysfunction in SC and to poor skills in EF. The aim of the present experimental study is to compare the impact of two very targeted child-oriented trainings in the increasing of social competence and decreasing of EB in preschoolers. One training targeted SC abilities while the second one targeted EF capacities. These two trainings were compared on 48 preschoolers presenting clinically relevant levels of EB. The comparison of those results highlighted how each training could help preschoolers with EB in their behavior, emotion regulation and social adjustment. In comparison to a waitinglist control-group, the two trainings were effective in decreasing EB and differentiated impacts of the two trainings were obtained on different dimensions of profiles of social competence and emotion regulation. Results are discussed for their research and clinical implications.
\end{abstract}

\section{Keywords}

Externalizing Behavior, Preschoolers, Social Cognition, Executive Functions, Training, Emotion Regulation

\section{Introduction}

During childhood, externalizing behaviors (EB) are displayed as agitation, hyperactivity, impulsivity, opposition, emotional instability, provocation, resistance, 
aggressiveness, or irritability. Among children, EB vary depending on intensity, occurrence but also on modalities.

EB result from neurological, developmental, environmental and parenting factors [1] [2]. Researchers have highlighted individual and environmental risk factors that could be responsible of the likelihood of EB at preschool age [e.g.] [3]. Individual risk factors include notably social cognition (SC) and executive functions (EF).

A high level of EB has usually been related to dysfunction in SC and to deficits in social problem solving situations [4] [5]. Furthermore, EB problems are associated with emotion regulation in children for a review, see [6], skills in social interactions with peers and adults [7] and also with social adjustment [8]. There is a necessity to detect EB in preschoolers and intervene during the preschool period. Indeed, it is known that emotion regulation difficulties could explain EB in preschoolers, and EB could predict antisocial behaviors, social maladjustment and mental health problems in later years [9] [10].

Several models enlighten the development of SC, linked to social interactions with adults and peers or emotion regulation and social adjustment. Some of them contribute to better understand how deficits in SC could impact the social maladjustment in children and EB disorders at preschool age. In the current study, we refer to the Theory of Mind (ToM) and the Social Information Processing (SIP) models. ToM conceptions include the capacity to understand one's own and other's mental states, to infer other's mental states and then to adapt one's behavior to others social situations [11] [12]. Some studies have identified deficits in children with EB in the recognition of emotions and the understanding of causes and consequences of emotions [13] [14] [15], difficulties in interpreting other people's behavioral intentions [16], or deficits in the understanding of beliefs [17] [18].

The SIP model explains how children use SIP in order to act in a social situation through five steps. First, children encode other people's social cues 1), and interpret social cues 2) before clarifying goals 3 ). After that, they access or build a response 4), and they make a response decision 5) [8]. Deficits in children with EB have been postulated in each of the five steps of SIP [8] [19] [20] [21], and these deficits become worse with time [22]. These difficulties in ToM or SIP may contribute to social maladjustment [23] [24].

Beside, several researches have shown a significant link between poor EF and EB in both typically developing and preschoolers with EB. Two meta-analyses [25] [26] showed that symptoms of inattention or hyperactivity disorders or of EB are associated with poor attention-vigilance, interference control and inhibition capacities (more precisely, it is mainly inhibition that correlates with EB). For instance, a higher error rate in inhibition tasks is generally observed in EB populations [27]-[34]. Furthermore, in unselected sample of preschoolers, poor EF capacities can predict EB one year later [35], two years later [36] or even up to three years later [37]. 
Several researchers have tried to manipulate SC abilities of children (in reference to ToM and SIP models) by implementing training and showed that it could be effective for children at risk for EB or presenting EB. In particular, after a ToM training, mostly targeting the understanding of emotions, children's level of socio-emotional competences increased [38]-[43]. An improvement in social problem solving was also obtained after a training program in which children discussed stories about peer interactions and performed related activities [44] or after children had been involved in role playing [40] [45]. In a recent experimental study, we developed an original training combining a ToM training (not only focusing on "emotions" or "beliefs") with a SIP training (focusing on the five steps of SIP). We showed that receiving this combined training let to better ToM abilities, more appropriate emotion regulation, and improved social adjustment and competences in preschoolers relative to a control-group [46].

Similarly, several training programs aiming at boosting children's EF capacities have been developed and showed that it is possible to improve overall EF in preschoolers [47] or to improve specifically inhibition [48] [49] [50] or working memory [50] [51]. Only two experimental studies have evalued the impact of an EF training on preschoolers with EB. Firstly, Tamm, Nakonezny [52] found a positive impact of their EF training on the child's attention, but not on symptoms of impulsivity or hyperactivity, nor on inattentive and hyperactive behaviors at school, measured by the parents and clinician's rating. However, this study did not target specifically EF (e.g., memory, hand-eye coordination, etc. were trained as well) and parents were given principles of behavior modification techniques to help them intervene at home. So, it does not allow defining what part of the program was really effective. Finally, there is no comparison with a control group. Recently, we developed a program targeting inhibition specifically and found that preschoolers with EB who started the training with a lower level of inhibition profited the most from the training and that children who received the inhibition training showed a larger decrease of their EB than children who took part in a control group [53].

All of the intervention studies mentioned here above considered either the SC or the EF. However, several researches have shown that these cognitive dimensions are not independent from one another. Significant correlations between measures of these two dimensions have been reported e.g., [54] [55] [56]. Furthermore, Kloo and Perner [57] investigated the transfer of training between ToM and EF and found a reciprocal effect after a very short training in one session. These authors explained this interdependence between the two processes by the fact that understanding the mind presupposes a certain level of executive control, and inversely executive control presupposes a certain level of insight into the mind. All of those studies had fostered the development of trainings which combine lots of competences in SC or in EF, but unfortunately, they concern numerous (social) cognitive functions and are not restricted to ToM, SIP, or inhibition [58] [59], preventing from identifying which trained functions enhance positive behavior. 
The goal of the present study is to compare the impact of two very targeted child-oriented trainings, one centered on social cognition and the other on executive functions, on the increase of social competence and the decrease EB in preschoolers. These two trainings were compared to a waiting-list control condition in a pseudo-randomized trial concluded on 48 preschoolers presenting clinically relevant levels of EB. More specifically, we examined the impact of these trainings on the child's behavior, emotion regulation and social adjustment. We also wanted to identify the impact of one training on the other cognitive domain. Indeed, as suggested by Kloo and Perner (2007), the interdependence in the development of EF and ToM might lead to a positive impact of an executive function training on social cognition and vice versa.

In previous studies, as explained before, we tested separately the impact of a SC training, and the impact of an EF training. The originality of the present study is its strict comparison of the impacts of two child-oriented trainings related to specific targeted processes, and the comparison with a control group, matched on some individual characteristics (age, IQ, EB level, etc.). The waiting-list control group allowed us to account for a potential time effect due to spontaneous development, as we know that the preschool period is critical for the development of these cognitive processes. Furthermore, the use of a multi-method procedure of EB evaluation (including an observational measure and two indirect measures) enables us to determine which specific type of behavior is reduced by either social cognition or EF training.

Based on the literature, both trainings are expected to be effective in reducing preschooler's EB [46] [60]. However, in the present study, we predicted differentiated impacts of SC and EF trainings, on the decrease of EB and on distinct dimensions of the profiles of social competence and emotion regulation. The possible observation of differentiated efficiency could possibly be very important for clinicians to determine, on the basis of a specific EB and socio-emotional profile, which training could be more appropriated.

\section{Method}

\subsection{Participants}

Data were collected from 48 preschoolers (54.1\% boys) aged between 3 years and 2 months and 5 years and 11 months old $(M$ age $=52.33$ months, $\mathrm{SD}=9.03$ months). Parents' level of education was evaluated on a scale (from elementary school not completed to university. In average, mothers indicated 5.40 (SD = 1.47) (5 corresponded to " 3 years of Graduate school" and 6 to " 5 years of Graduate school”) and fathers indicated 4.96 (SD = 1.48).Concerning the family's monthly income, parents has to specify it on a scale from " 0 - 500€" to " $4000 €$ or more", with a mean on $7.34(\mathrm{SD}=1.95)$ (7 corresponding to 3000 $3500 €$ a month). The native language of participants was invariably belgian and they were all Caucasians. Parents were informed about the study thanks to the media, pediatricians, and schools. Parents who wanted to participate and who 
had problems with their child's behavior had to fill in an online questionnaire including items of the Child Behavior Checklist CBCL, [61]. To be enrolled in the study, they have to obtain a score of minimum 21 ("borderline" or "pathological" level of the EB scale). Our exclusion criterion was a developmental delay or intellectual disabilities. Parents received an information letter and a consent form for the child's participation. A total of 54 participants were initially included in the study but after matching them for age and sex between groups, 6 subjects were excluded from analyses.

\subsection{Procedure}

Three phases composed this research. For the first phase (pre-test session), the intellectual quotient (IQ) and the EB level of each child were assessed by an experimenter across two sessions. Moreover, parents completed several questionnaires. Then, during the phase 2, children were randomly allocated to one of the three groups: 16 children received training on executive functions (experimental EF group), 16 other children took part in training on social cognition abilities (experimental SC group), and 16 others children were allocated to an eight-week waiting list. For ethical reasons, these children received another intervention after the phase 3 (post-test session) (see Figure 1). Except for the sessions content, the same procedure was followed in the two experimental groups. During 8 weeks, children participated in small groups ( 3 - 4 children) in 15 training sessions of 45 minutes. Several games were for the whole group, while others were for pairs. Within each group, sessions were administered by the two same experimenters. At the end of the trainings, parents completed the same questionnaires

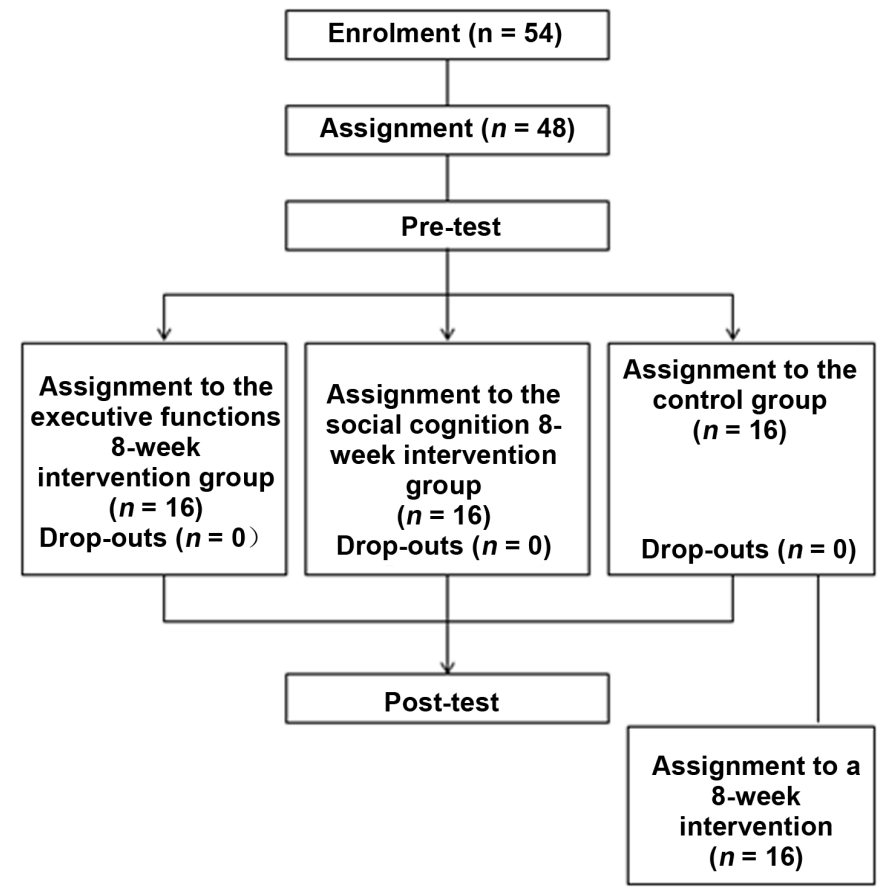

Figure 1. Flow of participants through each step of the study. 
as in pre-test and children's behavior was assessed through an observational paradigm by an experimenter who did not deliver the training and was blind of the group in which the child belonged to.

The content of the SC training was the same as the one used in Houssa and Nader-Grosbois [62]. Based on a theoretical background and on a hierarchical progression, the 7 first sessions dealt with ToM competences; then the 7 next dealt with SIP abilities; and the last session integrated all of the concepts in the training. The first part of the training was based on the program of Howlin and colleagues [63], which establishes a progression in the understanding of mental states. For the understanding of emotions are: 1) photographic facial recognition, 2) schematic facial recognition, 3) situation-based emotions, 4) desirebased emotions, 5) belief-based emotions. The level for beliefs are: 1) simple perspective taking, 2) complex perspective taking, 3) seeing leads to knowing, 4) true belief/action prediction, 5) false belief [64]. The second part of the SC training was based on the different steps of the SIP model [8]. This functional approach describes five steps in helping children to think about and resolve social problems. The training was also inspired by the levels of justification in the "social problem solving task" (RES, [65]). Authors detail three levels of justification with raising complexity: 1) the descriptive level (children describe the facts), 2) the inter-subjective level (a position associated to social consciousness), 3) the conceptual level (children stand back from the context and make reference to a convention or a social rule). During the training, we tried to elicit a more complex level of justification (in reference to the proximal zone of development conceptualized by Vygotsky [66]) by questioning children and giving feedbacks and in reference to the child's level. By completing other children's answers or correcting them, a socio-cognitive conflict was induced in children. Moreover, we asked questions to stimulate conversations and we gave feedback after answers. Activities involved sequences of play, video extracts, puppets, pictures, the handling of objects, story reading, etc. Each session ended with a story dealing with an emotion, a false belief or a social problem solving situation, providing an opportunity to talk about protagonist's mental states [44] [67]. More details about the program are available in two articles [46] [68].

The training focusing on EF was the same as the one used by [53]. It included games or exercises tapping mainly on the four dimensions of inhibition: interruption of an ongoing response, inhibition of external distractors and inhibition of a predominant response and impulsivity control. As for the SC training, particular accent was placed on the proximal zone of development [66]. Along the training, the difficulty level of the games increased. For instance, in a typical Stroop game where children saw a pair of animals drawn on a cardboard and were asked to show which one is the bigger in reality; the cards could be presented with a higher speed in later sessions. The rules of the games could also be more complex by involving some flexibility component for instance. So, children could be asked to select the animal that is bigger in reality except if the picture is framed. In that case, they should say which one is the bigger drawing on the 
cardboard. Progressively, fictional characters were presented to improve their metacognition of EF. These characters were inspired by an intervention method that uses characters to represent the EF (Reflecto; [69]). First, the policeman illustrating the verbal instruction: "Stop: first I think and then I do" was introduced. This character helped children in exercises implicating inhibition of a predominant or ongoing response, reminding children to avoid impulsive answers. The, the statue was introduced and used in exercises in which children needed to control their movements and keep calm. Finally, the detective allowed children to check one's own and other's performances during each exercise. Continually, children received feedback on their performance through the three characters. More details of the program are available in two articles [53] [70].

\subsection{Instruments}

\subsubsection{Measures of Individual Characteristics}

Wechsler Intelligence Scales-third edition [71]. Two subscales of the Weshler intelligence scale were used, one from the verbal IQ, the "information" scale, and one from the non-verbal IQ, the "block design" scale. Concerning the validation, the inter-correlations between raw scores on all scales were high [71]. To take part in the study (inclusion criterion), children had to be in the normal range, i.e., to have a global score (mean of the two subscales standard scores) between 5.5 and $14.5( \pm 1.5 \mathrm{SD})$.

\subsubsection{Measures of Externalizing Behavior}

Child Behavior Checklist (CBCL; [61]). The CBCL includes notably items to assess behavioral problems in children. To assess the level of EB deficit, parents were requested to fill in the CBCL. In the current study, we selected items related to $\mathrm{EB}$ to ensure that children actually presented $\mathrm{EB}$, i.e., that they were borderline (21 - 24) or pathological (>25) on the EB scale. The "Aggressive behavior" subscale (e.g., "my child is defiant") and the "Attention problems" subscale (e.g., my child can't concentrate") of the CBCL were added to determine the "Externalizing behavior" score for each child. CBCL scales have an internal consistency between 0.63 and 0.86 and a test-retest reliability of 0.85 .

The Unfair Card Game [72]. The Unfair Card Game (UCG) is derived from an adult paradigm focusing on perspective-taking [73] and is established on a computer game where the child is filmed playing with a virtual child (Thomas). In the first part, this game induces spontaneous positive affects and induces frustration in the second part. We invite the child to play where he/she can win candies. Two cards are shown on the screen in front of the child (one with a picture of a candy) and then the cards turn over and start to move. After that, the cards stop moving and the experimenter asks the child to show the card with the candy. During five rounds, for each correct answer, the child gives a candy to Thomas (the virtual partner). Then the roles are reversed; it is Thomas' turn to play. We explain to the child that he will receive a candy for each of Thomas's correct answers. Because the UCG is a rigged game, the child wins his/her five 
rounds and therefore Thomas wins five candies, but Thomas wins only the first round and fails the four others. The child receives one candy. At the end, the level of frustration of the child returns to normal because Thomas tells the child that he played badly and that he will give him some candies. Thanks to standardized guidelines, four aspects are coded: positive affect (smile, laughter, etc.), negative affect (tears, insults, etc.), agitation (movements) and inattention (distraction). The intensity and the frequency of each aspect is coded using a five points scales (between $1=$ neither intense nor frequent and $5=$ very intense and frequent). Trained independent coders encoded (they did not know the group in which children were). The intercoders' reliability (weighted Kappa coefficient) achieves 0.766

\subsubsection{Measure of Theory of Mind and Executive Functions}

Theory of Mind Inventory (ToMI) [74] [75]. This questionnaire evaluates caregivers' perceptions of the understanding of mental states of children from 2 to 12 years old. The ToMI is composed of 39 items assessing emotions, beliefs, desires, intentions or perception (e.g., "my child recognizes when someone needs help", "my child recognizes when others are happy"). The French version matched the validation of the original version. Test-retest reliability $(r=0.86)$ and internal consistency $(\alpha=0.94)$ are very significant [75].

Childhood Executive Functioning Inventory [76]. This parental questionnaire measures the executive functioning of children. 24 items composed this questionnaire, scored on 1-to-5 point Likert-type scales, evaluating two factors: inhibition (e.g., "my child has difficulty refraining from smiling or laughing in situations where it is inappropriate") and working memory (e.g., my child easily forgets what he/she is asked to fetch"). For each factor, a mean is calculated. The French version presents a good internal consistency (between 0.85 and 0.89 ) and a high test-retest reliability was also established (between 0.75 and 0.87 ).

\subsubsection{Measures of Socio-Affective Profile and Social Adjustment}

The Social Competence and Behavior Evaluation (SCBE) [77]. The SCBE evaluates the social and affective skills needed for social adjustment in children from 2.5 to 6 years old and is used to identify possible externalizing or internalizing problems. The questionnaire is composed of 80 statements distributed into eight basic subscales and four global SCBE components (e.g., "my child should be the first", "my child shares his/her toys with other children"). For each score, the higher the score, the less difficulties the child has. In the current study, we used the basic subscales (i.e., aggressive-controlled, angry-tolerant, egoistic-prosocial, resistant-cooperative) and two global components (social competence and externalizing problems) which are pertinent to EB children. The French version of the SCBE showed good properties with a high inter-judge agreement, high internal consistency and good test-retest correlations.

Social adjustment scales-Echelles d'adaptation sociale pour enfants (EASE), [78]. This questionnaire is completed by parents and evaluates their perceptions 
of children's socio-emotional adjustment competencies. The EASE is composed of items relating to social competence (e.g., "my child knows that certain words should not be used") and items relating to children's mental states understanding capacities and perspective-taking competencies (e.g., "my child is capable of engaging in pretend play"). The EASE has good internal consistency ( $\alpha=0.77$ for items related to social competence, and $\alpha=0.79$ for items related to children's ToM).

\subsubsection{Measure of Emotion Regulation}

Emotion Regulation Checklist (ERC; [79] [80]). This questionnaire evaluates adult's perception of children's ER abilities in daily life through 24 items (e.g., "my child is empathic towards others", or "my child is easily frustrated"). Two scales composed the ERC: emotion regulation and emotion dysregulation. The French validation of the ERC matched those of the original version and showed good internal consistency, with a Cronbach's alpha for the emotion dysregulation subscale of .82 and for the emotion regulation subscale of .72. The correlation between these two scales is negative and significant $(r=-0.66, p<0.001)$.

\subsection{Data Analyses}

Preliminary analyses were leaded (one-way ANOVAs and chi squared test) to ensure the equivalence between groups before the trainings for socio-demographic data and for level of children's EB. Next, the efficiency of the trainings compared to the control group condition was measured through repeated measure ANOVAs on all measures with pre- and post-test scores as a two-level within-subjects factor of time and groups (SC group, EF group or control group) as a between-subjects factor.

\section{Results}

\subsection{Preliminary Analyses}

Table 1 resumes means and standard deviations for descriptive variables in the pre-test. As no significant difference was obtained between groups for children's age, IQ, level of EB, and mothers' and fathers' educational level, incomes, the three groups could be considered as equivalent before the training.

Moreover, there is no difference between groups in pre-test for social competence (SCBE, $F(2,44)=1.51, p=0.23)$, social adjustment $($ EASE, $F(2,44)=0.98$, $p=0.38)$, emotion regulation $(\mathrm{ERC}, F(2,44)=0.99, p=0.38)$, emotion dysregulation (ERC, $F(2,44)=1.07, p=0.35)$, inhibition (CHEXI, $F(2,44)=0.81, p=$ 0.45 ), working memory (CHEXI, $F(2,44)=0.61, p=0.55$ ), or for EB (CBCL, $F(2,45)=0.31, p=0.74)$. Means and standard deviations for each group are reported in Table 2.

\subsection{Effect of the Trainings}

To measure the training effects, repeated measures ANOVA were calculated on each of the dependent measures with one within-subject factor, the time 
Table 1. Means $(M)$ and standard deviations (SD) for each group in pre-test and between-group comparisons for demographic and individual characteristics.

\begin{tabular}{|c|c|c|c|c|}
\hline \multirow[t]{2}{*}{ Variables } & Control group $(n=16)$ & $\begin{array}{c}\text { Social cognition } \\
\text { experimental group }(n=16)\end{array}$ & $\begin{array}{c}\text { Executive functions } \\
\text { experimental group }(n=16)\end{array}$ & \\
\hline & $M(\mathrm{SD})$ & $M(\mathrm{SD})$ & $M(\mathrm{SD})$ & $\chi^{2} / F$ \\
\hline Sex (\% Male) & $62.5 \%$ & $37.5 \%$ & $62.5 \%$ & 2.68 \\
\hline CA (in months) & $52.19(9.85)$ & $49.38(8.62)$ & $55.44(8.03)$ & 1.87 \\
\hline IQ & $96.56(23.43)$ & $91.07(30.27)$ & $99.06(20.99)$ & 0.40 \\
\hline $\mathrm{EB}(\mathrm{CBCL})$ & $29.50(5.98)$ & $30.00(5.92)$ & $28.31(6.83)$ & 0.31 \\
\hline Mother's educational level & $5.50(1.51)$ & $5.50(1.51)$ & $5.20(1.47)$ & 0.21 \\
\hline Father's educational level & $5.44(1.36)$ & $4.63(1.54)$ & $4.77(1.48)$ & 1.38 \\
\hline Incomes & $7.63(1.78)$ & $7.50(1.75)$ & $6.87(2.53)$ & 0.66 \\
\hline
\end{tabular}

Note. $\mathrm{CA}=$ Chronological Age; $\mathrm{IQ}=$ Intellectual Quotient; $\mathrm{EB}=$ Externalizing Behavior (the higher the score, the higher the level of $\mathrm{EB}$ ); $\mathrm{CBCL}=\mathrm{Child}$ Behavior Checklist. Educational level: $1=$ non achieved primary school; $2=$ primary school; $3=$ secondary school; $4=$ apprenticeship; $5=3$ years of Graduate school; $6=5$ years of Graduate school; $7=$ university. Incomes: $1=0-500 € ; 2=500-1000 € ; 3=1000-1500 € ; 4=1500-2000 € ; 5=2000-2500 € ; 6=$ $2500-3000 € ; 7=3000-3500 € ; 8=3500-4000 € ; 9=4000 €$ and more.

Table 2. Means (M) and standard deviations (SD) on pre-test and post-test measures and their difference (with paired t-test) for each group and the Group $\times$ Time interaction of the ANOVAs (and associated eta 2).

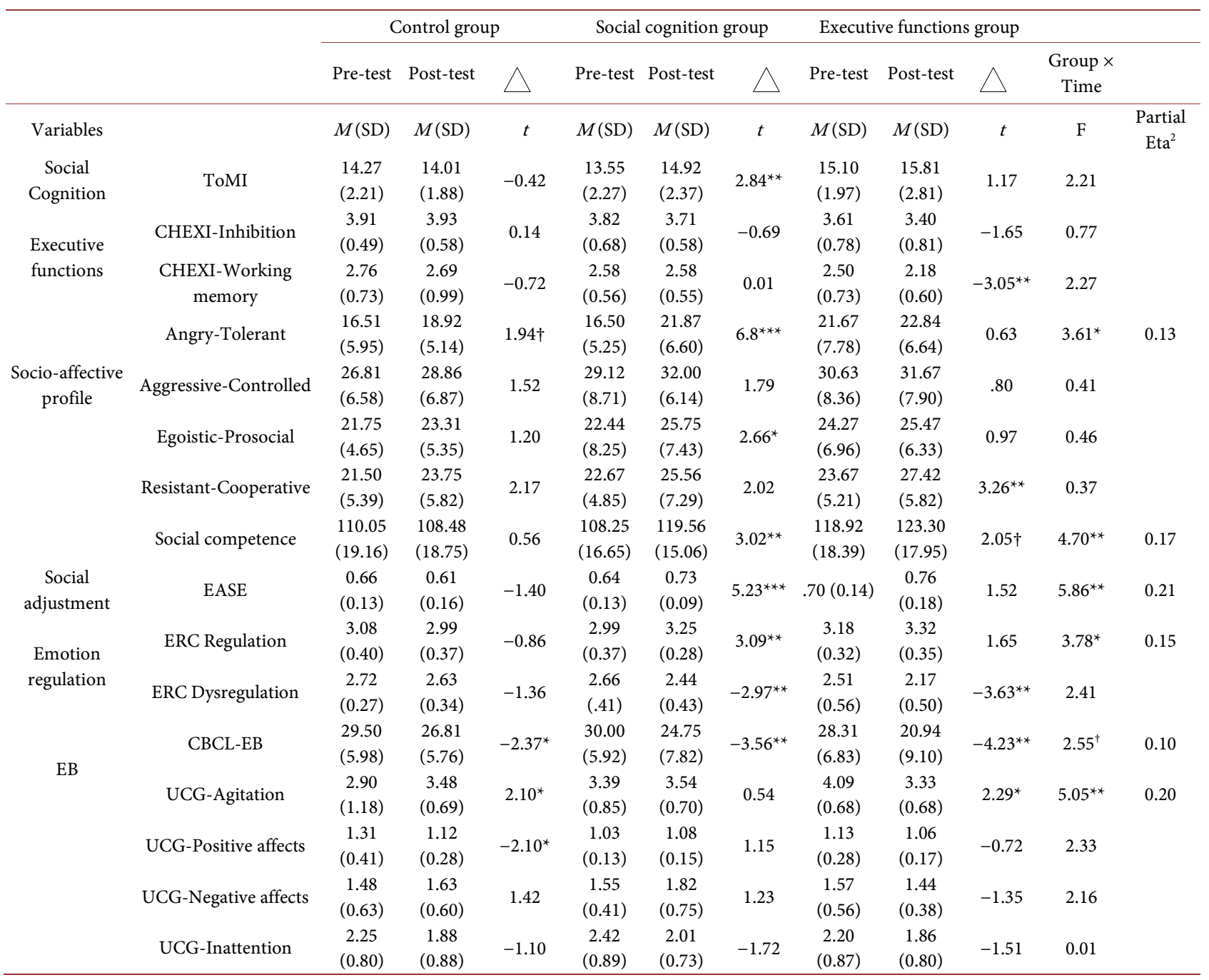

Note. $\Delta=$ post-test/pre-test difference. EASE = Social Adjustment Scales; ERC = Emotion Regulation Checklist; EB = Externalizing Behavior; UCG = Unfair Card Game; ${ }^{\star} p \leq 0.05,{ }^{* *} p \leq 0.01,{ }^{* * *} p=0.00$. 
(pre-test and post-test) and one between subjects factor, the group (SC, EF and control). Furthermore, as we were especially interested to see how much children improved from pre-test to post-test in each of the three groups, paired t-tests comparing pre- and post-training measures were systematically computed.

1) The targeted functions of the trainings

As shown in Table 2, the repeated measure ANOVA calculated on the ToMI score revealed no interaction or main effect of time $(F(1,42)=3.46, p=0.07)$ although paired-samples $t$ tests revealed that only children of the SC group are perceived by their parents as better understanding mental states (ToMI) after the training. The same analysis on the score of inhibition in the CHEXI also revealed no interaction or main effect of time $(F(1,46)=2.01, p=0.163)$, but revealed a main effect of time for working memory, $F(1,46)=4.00, p=0.05, \eta^{2}=0.08$. Paired-samples $t$ tests revealed significantly less working memory errors after the training for the EF group only.

2) Profiles of social competence

As shown in Table 2, the repeated measure ANOVA calculated on the angry-tolerant scale of the SCBE showed a significant group by time interaction. Paired-samples $t$ tests revealed that this interaction was due to a significant improvement in the SC group after the training, but not in the two others: the SC group was perceived as more tolerant and less angry. It is relevant to note that the SC group was under the clinical maladaptive threshold in pre-test, and above this threshold in the post-test (see Figure 2).

The ANOVA on the three others scales of the SCBE (aggressive-controlled, egoistic-prosocial and resistant-cooperative) failed to show any significant time by group interaction. However, paired $t$ tests revealed significant pre-post training change for the SC group only for aggressive-controlled scale $(F(2,46)=5.81$, $\left.p<0.01, \eta^{2}=0.12\right)$ and for egoistic-prosocial scale $\left(F(2,46)=7.66, p<0.01, \eta^{2}=\right.$ 0.15 ), indicating that those children are perceived as being less egoistic (or more

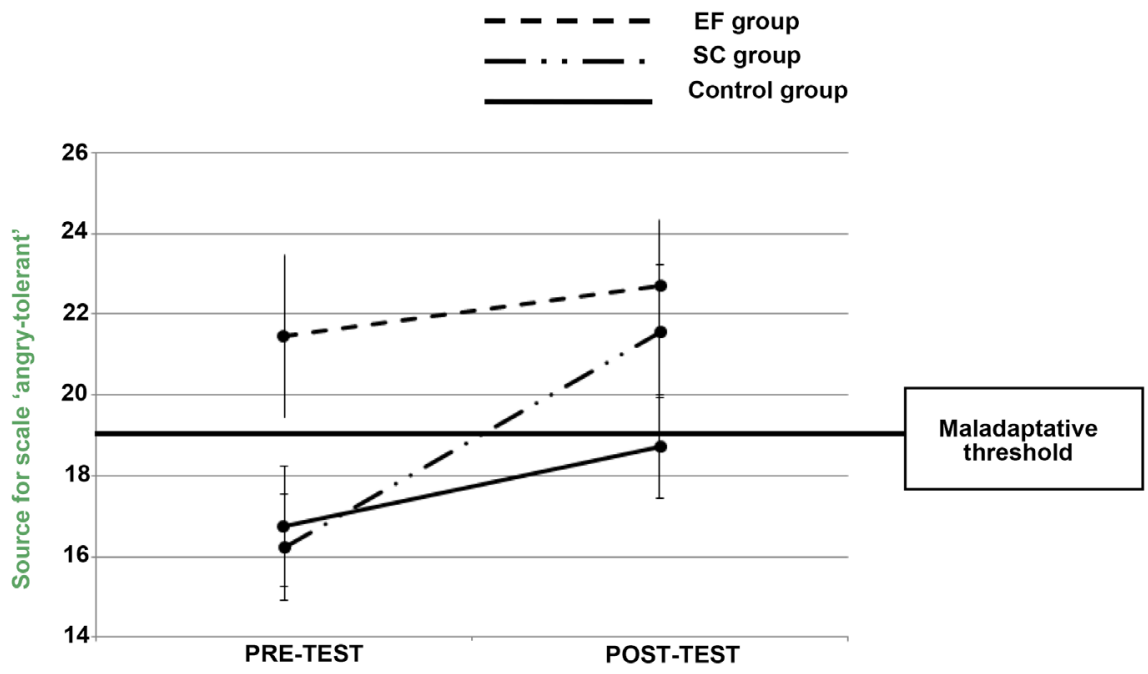

Figure 2. Profile plots "Pre-post-test ${ }^{\star}$ group" for the angry-tolerant scale of the SCBE (+standard error). 
prosocial). Furthermore, we found improvement in the EF group only for the resistant-cooperative scale $\left(F(2,46)=17.68, p=0.00, \eta^{2}=0.29\right)$ indicating that they were perceived as less resistant (or more cooperative) after the training.

The repeated measure ANOVA calculated on the social competence global component of the SCBE and calculated on the social adjustment score (EASE) also showed significant group by time interaction. Paired-samples $t$ tests revealed that children in the SC group showed significantly better social competence in the post-test than in the pre-test (see Figure 3). Paired-samples $t$ tests indicated that this interaction was due to a significant social adjustment improvement in the SC group only (see Figure 4).

3) Emotion regulation

A significant time by group interaction was observed as regards the emotion regulation score. Indeed, while emotion regulation abilities significantly decreased from pre-test to post-test for control children, they significantly increased in the EF training group (see Figure 5). Concerning the emotion dysregulation score, there a significant main effect of time $(F(2,46)=22.86, p=0.00$, $\left.\eta^{2}=0.34\right)$ but no significant group by time interaction. Yet, paired t-tests showed significant decrease of emotion dysregulation in both SC and EF groups but not in the control group (see Figure 6). Effect sizes are respectively 0.74 for the SC group and .91 for the EF group.

4) Externalizing behavior

The repeated measure ANOVA (with time and group) conducted on the EB scale of the CBCL revealed a significant effect of time $(F(2,45)=36.11, p=0.00$, $\left.\eta^{2}=0.44\right)$ and a tendency for an interaction time by group. Paired-samples $\mathrm{t}$ tests indicated that each group significantly decreased their EB level (i.e., children had less $\mathrm{EB}$ at post-test, but in the case of the CBCL score, a decrease is

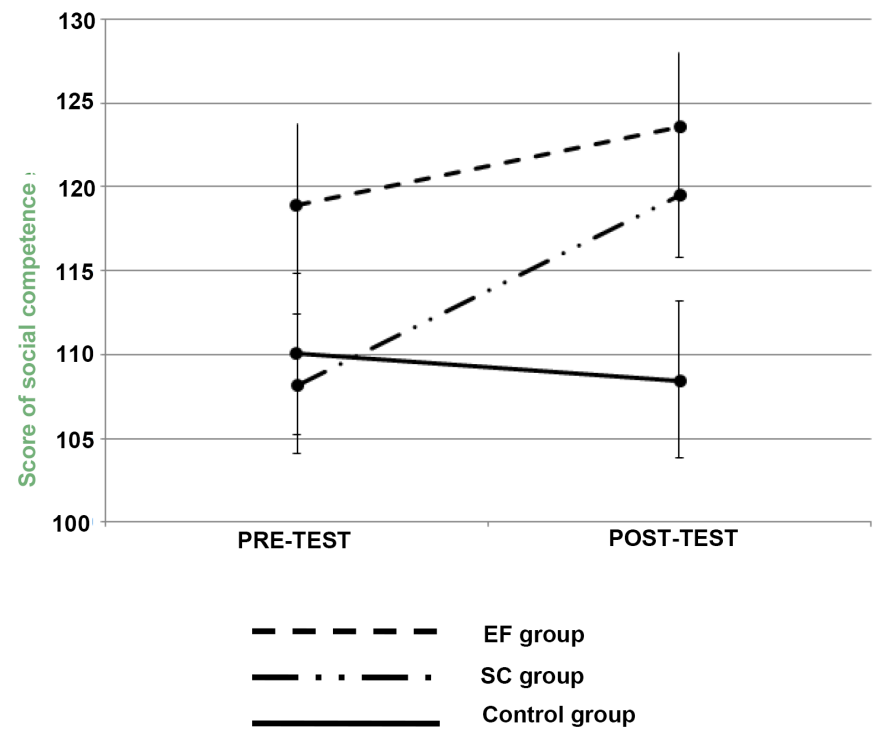

Figure 3. Profile plots "Pre-post-test * group" for the social competence score of the SCBE (+standard error). 


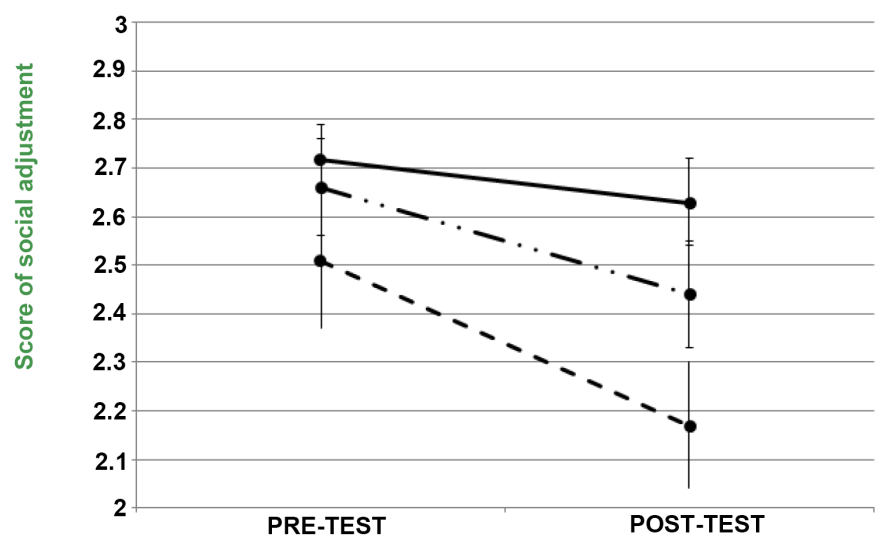

Figure 4. Profile plots "Pre-post-test * group" for the social adjustment score of EASE (+standard error).

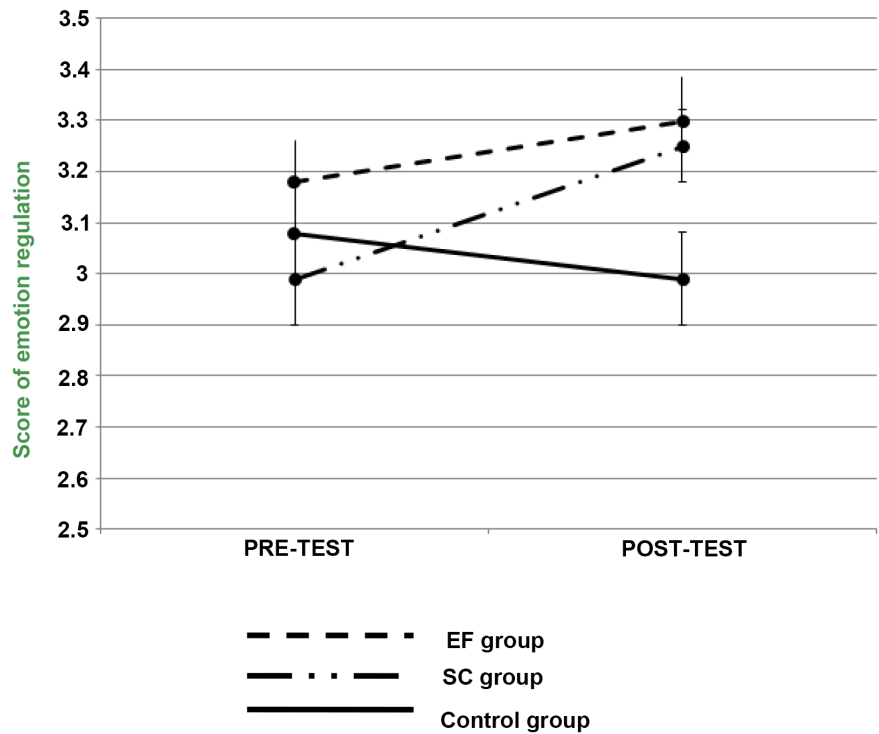

Figure 5. Profile plots "Pre-post-test * group" for the emotion regulation score (+standard error).

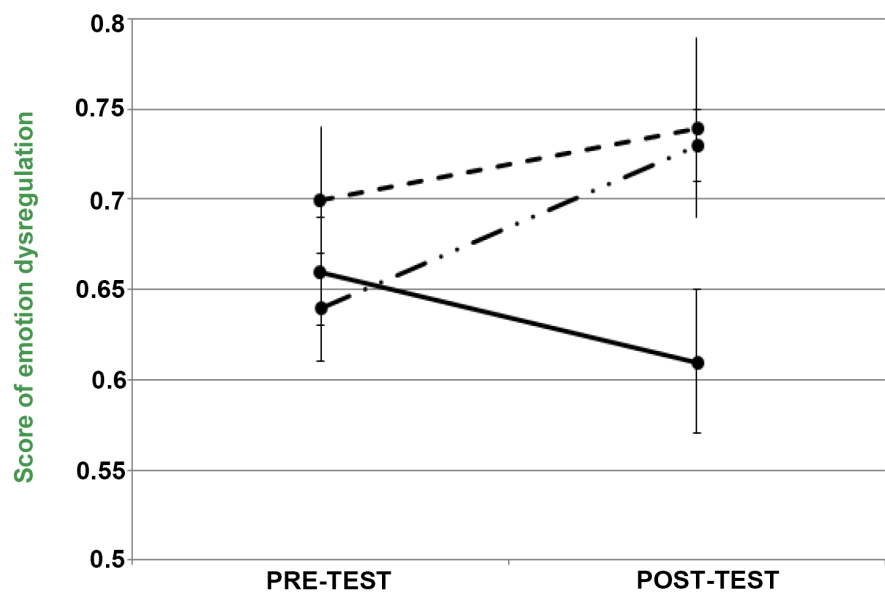

Figure 6. Profile plots "Pre-post-test ${ }^{\star}$ group" for the emotion dysregulation score (+standard error). 
expected). Effect sizes are respectively 0.59 for the control group, 0.89 for the SC group and 1.06 for the EF group.

Finally, repeated measures ANOVA made on the different scores of the UCG showed a significant group by time interaction only for the agitation score. Paired-samples $t$ tests indicated that only the EF group showed a significant decrease in agitation after the training. It is important to take note that the groups were not equivalent in pre-test $(F(2,43)=4.93, p<0.01)$ as the EF group was more agitated that the control group $(p<0.01)$ (see Figure 7 ).

\section{Discussion}

In this research, we compared the impact of two specific trainings, one targeting SC competences (Houssa \& Nader-Grosbois, [46] and the other targeting inhibition (Volckaert \& Noël, 2016) on preschoolers displaying clinically relevant level of EB. More precisely, we examined their effect in reducing EB and in increasing social adjustment and emotion regulation. These trainings were compared to a waiting list condition.

As several authors have shown, SC and EF are two variables previously associated with EB e.g., [4] [5] [25]. For example, the understanding of emotions predicted the level of EB [7] whereas children with EB showed a higher error level in EF tasks, especially those requiring inhibition [26].

As expected, the research highlights that the SC experimental group outperformed the others in ToM competences, while the EF experimental group outperformed the others in EF (particularly in working memory). Note that parents of the EF group did not report a change on their inhibition capacities. This could be due to the fact that in the current study, children were not selected according to their EF (or SC) difficulties but on the basis of their level of EB. Even if we

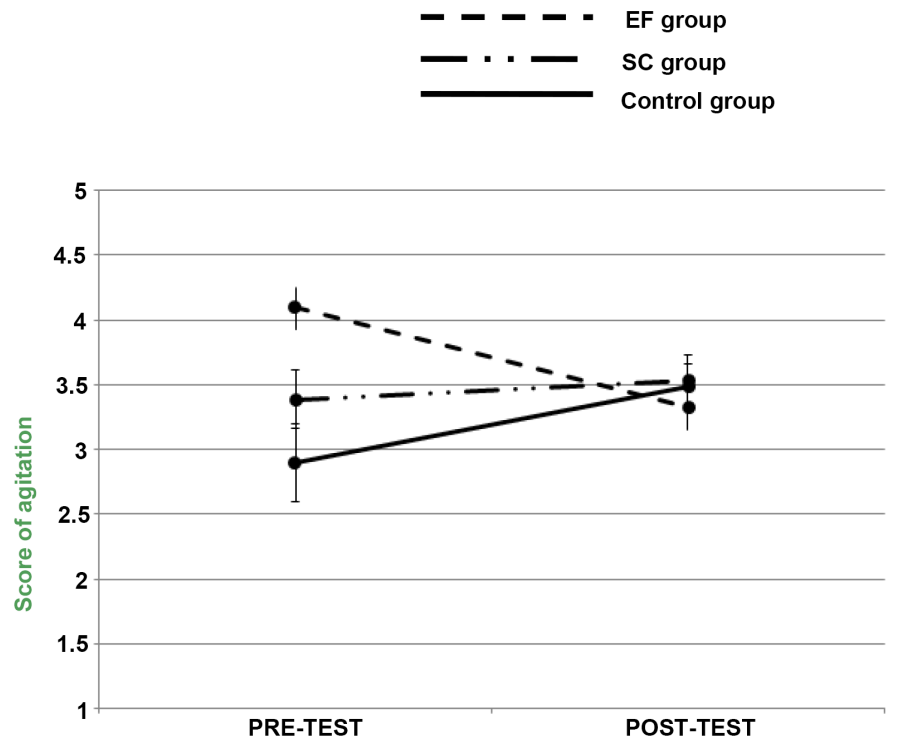

Figure 7. Profile plots "Pre-post-test * group" for the agitation score of the UCG (+standard error). 
know that EF problems are a risk factor for having EB, it is known that every child with EB does not present weak EF functions [53]. Others studies could use the same design but only with children having EB and poor EF.

Moreover, the fact that ToM competences only increased after the SC training and not after the EF training (and conversely) does not replicate the results of Kloo and Perner (2003) and is quite surprising given the link previously observed between EF and socio-cognitive abilities, notably on the understanding of (false) beliefs e.g., [81] [82]. Several differences between our study and Kloo and Perner's could account for this non-replication. Indeed, Kloo and Perner worked with typically developing children while we worked with preschoolers with high level of EB. Children participated in a unique session of training while our training included 15 sessions. Furthermore, Kloo and Perner's session in ToM included only one mental state (stories about false belief) and the session in EF was uniquely based on a card sorting task (children have to sort cards according to one dimension and second according to another dimension). Our results revealed rather that the components of the trainings were different, focused on specific targets and that an inhibition training did not induce necessarily an increase of diverse tasks in ToM of different mental states, and vice versa.

Finally, the two trainings induced different impacts on children's profiles in social competence and emotion regulation and level of EB. After a SC training, children were perceived by their parents as being less angry (or more tolerant), and, more moderately, less egoistic (or more prosocial) and as having more social competence and better social relationships after the training. This goes to the same way as researchers who previously showed links between EB and social adjustment e.g., [8] and with some others who obtained improvements in social competence after a training in SC e.g., [59]. After an EF training, children were described as being less resistant to adults (or more cooperative). From a clinical view, those results could be useful in helping aim those variables that need to be stimulated according to the socio-affective profile of the child. For example, in regards to our results, it seems that a child with EB who have a high level of aggressiveness could benefit more from a SC training than from an EF training. Inversely, a child with a high level of opposition could benefit more from an EF training.

Concerning emotion regulation, parents of children of both experimental groups described their children as having more flexibility, mood lability and as better regulating negative affect. In other words, emotion dysregulation decreased. Specifically, after the SC training, parents perceived their children as finding it simpler to express adaptive emotions in everyday situations, to regulate better their emotions and as displaying more empathy. These results show that it is possible to help preschoolers to improve their emotion regulation by these distinct trainings. It is particularly interesting given emotion regulation difficulties could be responsible of EB in preschoolers [9] [10].

Finally, concerning the impact of each training on the level of EB assessed by 
parents, the results revealed that the reduction of the level of EB was not explained by the delivery content of each training. Rather, it suggests that some efficient solutions exist for decreasing EB in preschoolers. In particular, taking care of the children in small groups and training their abilities to understand mental states and solve critical social situations, or to control impulsive behaviors allow children to manifest less often their EB. Furthermore, both trainings could have enhanced the tendency to have positive relationships with parents, teachers and peers, leading to reinforce the probability to continue to use their new competences. It is relevant to note that children of the control group also decrease their level of EB. This could be due to the sense of help parents felt from the research team when they signed up for the study.

For the EF training, the parental ratings about EB were corroborated with an observational paradigm (UCG) which is a more objective measure. It is important to note that this measure exclude any possible bias relative to the experimenter's expectations because the coder for UCG was not informed about the research and blind to the group in which children were. This means that taking care of children in groups and making exercises that allow them to become cognizant of their cognitive (self-) control though the characters and use them in exercises lead to significant diminution of their EB (especially agitation). Concerning the others dimensions of the UCG (positive affect, negative affect or inattention), we did not observe any impact of one of the two trainings.

This research highlights that stimulating EF in preschoolers with EB has a larger impact on the level of EB (reported through several measures), while stimulating SC competences has a larger impact on children' social adjustment and socio-affective profile. In other words, training SC was more effective for increasing SC competences, which in turn have an impact on their tolerance, their prosocial behavior, their social competence and social adjustment, their emotion regulation and dysregulation, and their level of EB. Training inhibition was rather more effective for increasing EF, which in turn results in better behavioral outcomes in children like their increase in cooperative behavior, their decrease of emotion dysregulation, and their diminution of EB level.

\section{Limitations}

Several limitations have to be recognized and overcome in future studies. First, children from the current study are considered as having a clinically relevant level of EB through the parental evaluation, but not through a diagnostic made by a professional. Include an objective evaluation of EB would be useful for others researches to assure that the behaviors problems reported by parents really represented EB.

Secondly, besides the parental report (CBCL) and the observational measure (UCG), it would have been interesting to have the teachers' report in order to have a multi-informant and multi-environment approach. It is however important to note that we did ask teachers to fill in questionnaires in both pre- and 
post-test but unfortunately the very small return rate prevented any valuable analyses from being done.

Thirdly, EB is a complex entity whose nature is sometimes oversimplified [83]. The CBCL [61] is widely used as a global measure of EB. However, another measure of EB such as the SCBE [77] might be interesting to use in further research as it allows to measure different dimensions of EB such as aggressiveness, irritability, emotional instability, etc.

\section{Conclusions}

In conclusion, this is the first comparison between two child-oriented trainings targeted to reduce EB in preschoolers. The current comparison between these two trainings revealed that they are both effective in reducing EB in preschoolers, with specific effects depending on each training. Those results allowed practitioners to adjust their intervention to the strengths and weaknesses of the child, and to the targeted competences. Furthermore, in view of large and comparable effect sizes on EB, focused interventions on several months seem to be reasonable alternative to long-term multimodal programs e.g., Incredible Years; [84], proposing more cost-effective intervention. In our study, effect sizes were respectively 0.59 for the control group, 0.89 for the SC group and 1.06 for the EF group.

The length of training (eight weeks) seems to be satisfactory to obtain a large decrease of EB. Furthermore, it seems not necessary to deliver multimodal trainings which stimulate numerous variables together. In this study, children were randomly assigned to one of the two training groups. However, in a clinical setting, the child's competences and difficulties could be evaluated, i.e., his/her socio-affective profile, his/her abilities in social cognition, in EF, in social adjustment and in emotion regulation to identify which of these factors needs to be supported by a specific training. Roskam, and collaborators [3] explained that EB is associated with several risk factors, but that none of these is present in all children with EB. Then, identify the specific weakness of the child may be even more effective in the training.

Finally, psychologists or preschoolers teachers could be trained (with training manuals and videos) to implement those two types of trainings to prevent or intervene with preschoolers. Moreover, train parents to several techniques used in both trainings when games, visual supports, the three characters, etc. are used could help to consolidate some acquired skills and reinforce their efficacy.

\section{Acknowledgements}

This project was supported by a concerted research action on externalizing behavior (Convention ARC 11/16-038). We are grateful to the children and their parents for their involvement. Finally, we thank our sponsors for all the gifts we have been able to give to the families. 


\section{Conflict of Interest and Ethical Committee}

There is no conflict of interest in this research. This study is approved by the ethical committee of the Université catholique de Louvain (Belgium).

\section{References}

[1] Owens, E.B. and Shaw, D.S. (2003) Predicting Growth Curves of Externalizing Behavior across the Preschool Years. Journal of Abnormal Child Psychology, 31, 575-590. https://doi.org/10.1023/A:1026254005632

[2] Roskam, I., Kinoo, P. and Nassogne, M.-C. (2007) L'enfant avec troubles externalisés du comportement: Approche épigénétique et développementale. [Children Displaying Externalizing Behaviour. Epigenetic and Developmental Framework.] Neuropsychiatrie de l'enfance et de l'adolescence, 55, 204-213. https://doi.org/10.1016/j.neurenf.2007.01.005

[3] Roskam, I., et al. (2013) When There Seem to Be No Predetermining Factors: Early Child and Proximal Family Risk Predicting Externalizing Behavior in Young Children Incurring No Distal Family Risk. Research in Developmental Disabilities, 34, 627-639. https://doi.org/10.1016/j.ridd.2012.10.002

[4] Pettit, G.S., Dodge, K.A. and Brown, M.M. (1988) Early Family Experience, Social Problem Solving Patterns, and Children's Social Competence. Child Development, 59, 107-120. https://doi.org/10.2307/1130393

[5] Denham, S.A., Zinsser, K. and Bailey, C.S. (2011) Emotional Intelligence in the First Five Years of Life. In: Trembay, R.E., Boivin, M. and Peters, R.DeV., Eds., Encyclopedia on Early Childhood Development, Centre of Excellence for Early Childhood Development and Strategic Knowledge Cluster on Early Child Development, Montreal.

[6] Southam-Gerow, M.A. and Kendall, P.C. (2002) Emotion Regulation and Understanding: Implications for Child Psychopathology and Therapy. Clinical Psychology Review, 22, 189-222. https://doi.org/10.1016/S0272-7358(01)00087-3

[7] Nader-Grosbois, N., Houssa, M. and Mazzone, S. (2013) How Could Theory of Mind Contribute to the Differentiation of Social Adjustment Profiles of Children with Externalizing Behavior Disorders and Children with Intellectual Disabilities? Research in Developmental Disabilities, 34, 2642-2660.

https://doi.org/10.1016/j.ridd.2013.05.010

[8] Crick, N.R. and Dodge, K.A. (1994) A Review and Reformulation of Social Information-Processing Mechanisms in Children's Social Adjustment. Psychological Bulletin, 115, 74-101. https://doi.org/10.1037/0033-2909.115.1.74

[9] Campbell, S.B. (2006) Behaviour Problems in Preschool Children: Clinical and Developmental Issues. Guilford Press, New York.

[10] Faivre, L.F., et al. (2005) Troubles du comportement entre 18 et 36 mois: symptomatologie et psychopathologie associées. [Behavior Disorders in Toddlers: Symptomatology and Psychopathology.] Neuropsychiatrie de l'enfance et de l'adolescence, 53, 176-185. https://doi.org/10.1016/j.neurenf.2005.04.001

[11] Deneault, J. and Ricard, M. (2013) Are Emotion and Mind Understanding Differently Linked to Young Children's Social Adjustment? Relationships between Behavioral Consequences of Emotions, False Belief, and SCBE. The Journal of Genetic Psychology, 174, 88-116. https://doi.org/10.1080/00221325.2011.642028

[12] Flavell, J.H. (1999) Cognitive Development: Children's Knowledge about the Mind. Annual Review of Psychology, 50, 21-45. 
https://doi.org/10.1146/annurev.psych.50.1.21

[13] Speltz, M.L., et al. (1999) Neuropsychological Characteristics and Test Behaviors of Boys with Early Onset Conduct Problems. Journal of Abnormal Psychology, 108, 315-325. https://doi.org/10.1037/0021-843X.108.2.315

[14] Blair, R.J.R. and Coles, M. (2000) Expression Recognition and Behavioural Problems in Early Adolescence. Cognitive Development, 15, 421-434. https://doi.org/10.1016/S0885-2014(01)00039-9

[15] Marsh, A.A. and Blair, R.J.R. (2008) Deficits in Facial Affect Recognition among Antisocial Populations: A Meta-Analysis. Neuroscience and Biobehavioral Reviews, 32, 454-465. https://doi.org/10.1016/j.neubiorev.2007.08.003

[16] Dodge, K.A. and Coie, J.D. (1987) Social Information Processing Factors in Reactive and Proactive Aggression in Children's Peer Groups. Journal of Personality and Social Psychology, 53, 1146-1158. https://doi.org/10.1037/0022-3514.53.6.1146

[17] Renouf, A., et al. (2010) Interactive Links between Theory of Mind, Peer Victimization, and Reactive and Proactive Aggression. Journal of Abnormal Child Psycholo$g y$, 38, 1109-1123. https://doi.org/10.1007/s10802-010-9432-Z

[18] Walker, S. (2005) Gender Differences in the Relationship between Young Children's Peer-Related Social Competence and Individual Differences in Theory of Mind. Journal of Genetic Psychology, 166, 297-312. https://doi.org/10.3200/GNTP.166.3.297-312

[19] Dodge, K.A. and Crick, N.R. (1990) Social Information-Processing Bases of Aggressive Behaviour in Children. Personality and Social Psychology Bulletin, 16, 8-22. https://doi.org/10.1177/0146167290161002

[20] Dodge, K.A. and Pettit, G.S. (2003) A Biopsychosocial Model of the Development of Chronic Conduct Problems in Adolescence. Developmental Psychology, 39, 349-371. https://doi.org/10.1037/0012-1649.39.2.349

[21] Mize, J. and Pettit, G.S. (2008) Social Information-Processing and the Development of Conduct Problems in Children and Adolescents: Looking Beneath the Surface. In: Sharp, C., Fonagy, P. and Goodyer, I., Eds., Social Cognition and Developmental Psychopathology, Oxford University Press, New York, 141-174. https://doi.org/10.1093/med/9780198569183.003.0006

[22] Dodge, K.A., et al. (2003) Peer Rejection and Social Information-Processing Factors in the Development of Aggressive Behavior Problems in Children. Child Development, 74, 374-393. https://doi.org/10.1111/1467-8624.7402004

[23] Crick, N.R. and Dodge, K.A. (1996) Social Information-Processing Mechanisms in reactive and Proactive Aggression. Child Development, 67, 993-1002.

https://doi.org/10.2307/1131875

[24] Eisenberg, N., et al. (1997) Contemporaneous and Longitudinal Prediction of Children's Social Functioning from Regulation and Emotionality. Child Development, 68, 642-664. https://doi.org/10.2307/1132116

[25] Pauli-Pott, U. and Becker, K. (2011) Neuropsychological Basic Deficits in Preschoolers at Risk for ADHD: A Meta-Analysis. Clinical Psychology Review, 31, 626-637. https://doi.org/10.1016/j.cpr.2011.02.005

[26] Schoemaker, K., et al. (2013) Executive Functions in Preschool Children with Externalizing Behavior Problems: A Meta-Analysis. Journal of abnormal Child Psychology, 41, 457-471. https://doi.org/10.1007/s10802-012-9684-x

[27] Berwid, O.G., et al. (2005) Sustained Attention and Response Inhibition in Young Children at Risk for Attention Deficit/Hyperactivity Disorder. Journal of Child 
Psychology and Psychiatry, 46, 1219-1229.

https://doi.org/10.1111/j.1469-7610.2005.00417.x

[28] Brophy, M., Taylor, E. and Hughes, C. (2002) To Go or Not to Go: Inhibitory Control in 'Hard to Manage' Children. Infant and Child Development, 11, 125-140. https://doi.org/10.1002/icd.301

[29] Fahie, C.M. and Symons, D.K. (2003) Executive Functioning and Theory of Mind in Children Clinically Referred for Attention and Behavior Problems. Journal of Applied Developmental Psychology, 24, 51-73. https://doi.org/10.1016/S0193-3973(03)00024-8

[30] Raaijmakers, M.A.J., et al. (2008) Executive Functions in Preschool Children with Aggressive Behavior: Impairments in Inhibitory Control. Journal of Abnormal Child Psychology, 36, 1097-1107. https://doi.org/10.1007/s10802-008-9235-7

[31] Mariani, M.A. and Barkley, R.A. (1997) Neuropsychological and Academic Functioning in Preschool Boys with Attention Deficit Hyperactivity Disorder. Developmental Neuropsychology, 13, 111-129. https://doi.org/10.1080/87565649709540671

[32] Hughes, C., Dunn, J. and White, A. (1998) Trick or Treat?: Uneven Understanding of Mind and Emotion and Executive Dysfunction in 'Hard-to-Manage' Preschoolers. Journal of Child Psychology and Psychiatry and Allied Disciplines, 39, 981-994. https://doi.org/10.1111/1469-7610.00401

[33] Sonuga-Barke, E.J.S., et al. (2002) Are Planning, Working Memory, and Inhibition Associated with Individual Differences in Preschool ADHD Symptoms? Developmental Neuropsychology, 21, 255-272. https://doi.org/10.1207/S15326942DN2103_3

[34] Youngwirth, S.D., et al. (2007) Neuropsychological Abilities of Preschool-Aged Children Who Display Hyperactivity and/or Oppositional-Defiant Behavior Problems. Child Neuropsychology, 13, 422-443. https://doi.org/10.1080/13825580601025890

[35] Hughes, C. and Ensor, R. (2008) Does Executive Function Matter for Preschoolers' Problem Behaviors? Journal of Abnormal Child Psychology, 36, 1-14. https://doi.org/10.1007/s10802-007-9107-6

[36] Bohlin, G., et al. (2012) Disorganized Attachment and Inhibitory Capacity: Predicting Externalizing Problem Behaviors. Journal of Abnormal Child Psychology, 40, 449-458. https://doi.org/10.1007/s10802-011-9574-7

[37] Berlin, L., Bohlin, G. and Rydell, A.-M. (2003) Relations between Inhibition, Executive Functioning, and ADHD-Symptoms: A Longitudinal Study from Age 5 to 8 . Child Neuropsychology, 9, 55-65.

[38] Merrell, K.W., et al. (2008) Social and Emotional Learning in the Classroom: Evaluation of Strong Kids and Strong Teens on Student's Social-Emotional Knowledge and Symptoms. Journal of Applied School Psychology, 24, 209-224. https://doi.org/10.1080/15377900802089981

[39] Izard, C.E., et al. (2008) Accelerating the Development of Emotion Competence in Head Start Children: Effects on Adaptative and Maladaptative Behavior. Development and Psychopathology, 20, 369-397. https://doi.org/10.1017/S0954579408000175

[40] Webster-Stratton, C., Reid, J. and Beauchaine, T. (2011) Combining Parent and Child Training for Young Children with ADHD. Journal of Clinical Child \& Adolescent Psychology, 40, 191-203. https://doi.org/10.1080/15374416.2011.546044

[41] Pears, K.C., Fisher, P.A. and Bronz, K.D. (2007) An Intervention to Promote Social Emotional School Readiness in Foster Children: Preliminary Outcomes from a Pilot 
Study. School Psychological Review, 36, 665-673.

[42] Domitrovich, C.E., Cortes, R.C. and Greenberg, M.T. (2007) Improving Young Children's Social and Emotional Competence: A Randomized Trial of the Preschool “PATHS" Curriculum. Journal of Primary Prevention, 28, 67-91. https://doi.org/10.1007/s10935-007-0081-0

[43] Sprung, M., et al. (2015) Children's Emotion Understanding: A Meta-Analysis of Training Studies. Developmental Review, 37, 41-65. https://doi.org/10.1016/j.dr.2015.05.001

[44] Bhavnagri, N.P. and Samuels, B.G. (1996) Children's Literature and Activities Promoting Social Cognition of Peer Relationships in Preschoolers. Early Childhood Research Quarterly, 11, 307-331. https://doi.org/10.1016/S0885-2006(96)90010-1

[45] Shure, M.B. and Spivack, G. (1982) Interpersonal Problem-Solving in Young Children: A Cognitive Approach to Prevention. American Journal of Community Psychology, 10, 341-356. https://doi.org/10.1007/BF00896500

[46] Houssa, M. and Nader-Grosbois, N. (2016a) Could Training Social Cognition Reduce Externalizing Behaviors in Preschoolers and Enhance Their Social Adjustment? Journal of Psychological Abnormalities, S1, 005.

[47] Röthlisberger, M., et al. (2011) Improving Executive Functions in 5- and 6-Year-Olds: Evaluation of a Small Group Intervention in Prekindergarten and Kindergarten Children. Infant and Child Development, 21, 411-429. https://doi.org/10.1002/icd.752

[48] Dowsett, S.M. and Livesey, D.J. (2000) The Development of Inhibitory Control in Preschool Children: Effects of 'Executive Skills' Training. Developmental Psychobiology, 36, 161-174. https://doi.org/10.1002/(SICI)1098-2302(200003)36:2<161::AID-DEV7>3.0.CO;2-0

[49] Diamond, A., et al. (2007) The Early Years: Preschool Program Improves Cognitive Control. Science, 318, 1387-1388. https://doi.org/10.1126/science.1151148

[50] Thorell, L.B., et al. (2009) Training and Transfer Effects of Executive Functions in Preschool Children. Developmental Science, 12, 106-113. https://doi.org/10.1111/j.1467-7687.2008.00745.x

[51] Klingberg, T., et al. (2005) Computerized Training of Working Memory in Children with ADHD-A Randomized, Controlled Trial. Journal of the American Academy of Child and Adolescent Psychiatry, 44, 177-186. https://doi.org/10.1097/00004583-200502000-00010

[52] Tamm, L., Nakonezny, P.A. and Hughes, C.W. (2012) An Open Trial of a Metacognitive Executive Function Training for Young Children with ADHD. Journal of Attention Disorders, 18, 551-559. https://doi.org/10.1177/1087054712445782

[53] Volckaert, A.M.S. and Noël, M.-P. (2015) Training Executive Function in Preschoolers Reduce Externalizing Behaviors. Trends in Neuroscience and Education, 4, 37-47. https://doi.org/10.1016/j.tine.2015.02.001

[54] Henning, A., Spinath, F.M. and Aschersleben, G. (2010) The Link between Preschoolers' Executive Function and Theory of Mind and the Role of Epistemic States. Journal of Experimental Child Psychology, 108, 513-531. https://doi.org/10.1016/j.jecp.2010.10.006

[55] Carlson, S.M., Mandell, D.J. and Williams, L. (2004) Executive Function and Theory of Mind: Stability and Prediction from Ages 2 to 3. Developmental Psychology, 40, 1105-1122. https://doi.org/10.1037/0012-1649.40.6.1105

[56] Van Nieuwenhuijzen, M., et al. (2015) Executive Functions and Social Information Processing in Adolescents with Severe Behavior Problems. Child Neuropsychology, 
1-14.

[57] Kloo, D. and Perner, J. (2007) Training Theory of Mind and Executive Control: A Tool for Improving School Achievement? University of Salzburg, Autriche.

[58] Tamm, L., Nakonezny, P.A. and Hughes, C.W. (2014) An Open Trial of a Metacognitive Executive Function Training for Young Children with ADHD. Journal of Attention Disorders, 18, 551-559. https://doi.org/10.1177/1087054712445782

[59] Joseph, G.E., Webster-Stratton, C. and Reid, J. (2006) Fostering Social and Emotional Competence: Implementing Dina Dinosaur's Social Skills and Problem Solving Curriculum in Inclusive Early Childhood Programs. Parenting Research Clinic.

[60] Volckaert, A.M.S. and Noël, M.-P. (2016) Externalizing Behavior Problems in Preschoolers: Impact of an Inhibition Training. Journal of Psychological Abnormalities, 5, 154.

[61] Achenbach, T.M. and Rescorla, L.A. (2000) Manual for the ASEBA Preschool Forms \& Profiles. University of Vermont, Research Center for Children, Youth, \& Families, Burlington.

[62] Houssa, M. and Nader-Grosbois, N. (2016) Experimental Study of Middle-Term Training in Social Cognition for Pre-Schoolers. Journal of Education and Training Studies, 4, 61-73.

[63] Howlin, P., Baron-Cohen, S. and Hadwin, J. (2011) Apprendre aux enfants autistes à comprendre la pensée des autres. [Teaching Children with Autism to Mind-Read. A Pratictical Guide by Patricia Howlin, Simon Baron-Cohen and Julie Hadwin.] De Boeck, Ed.

[64] Hadwin, J., et al. (1996) Can We Teach with Autism to Understand Emotions, Belief, or Pretence? Development and Psychopathology, 8, 345-365. https://doi.org/10.1017/S0954579400007136

[65] Barisnikov, K., Van der Linden, M. and Hippolyte, L. (2004) Tâche de résolution sociale. [Social Problem-Solving Task.] Manuel inédit, Genève.

[66] Vygotsky, I.S. (1978) Mind in Society. The Development of Higher Psychological Processes. Harvard University Press, Cambridge.

[67] Lecce, S., et al. (2014) Training Preschoolers on First-Order False Belief Understanding: Transfer on Advanced ToM Skills and Metamemory. Child Development, 85, 2404-2418.

[68] Houssa, M. and Nader-Grosbois, N. (2017) Stimuler les capacités en cognition sociale, in Traiter les troubles externalisés du comportement chez le jeune enfant. [Boost Social Cognitive Competences, in Treat Externalizing Behavior in Young Children.] Roskam, I., Nader-Grosbois, N., Noël, M.-P. and Schelstraete, M.-A., Eds., Wavre, Mardaga.

[69] Gagné, P.P. and Longpré, L.P. (2004) Apprendre... avec Réflecto. [Learn with Reflecto.] Chenelière/McGraw Hill.

[70] Volckaert, A.M.S., Noël, M-P. (2017) Stimuler les fonctions exécutives, in Traiter les troubles externalisés du comportement chez le jeune enfant. [Boost Executive Functions, in Treat Externalizing Behavior in Young Children.] Roskam, I., NaderGrosbois, N., Noël, M.-P. and Schelstraete, M.-A., Eds., Wavre, Mardaga.

[71] Weschler, D. (2004) WPPSI-III: Manuel d'interprétation. [WPPSI-III: Interpretation Manual.] Les Editions du Centre de Psychologie Appliquée, Paris.

[72] Roskam, I., et al. (2016) The Unfair Card Game: A Promising Tool to Assess Externalizing Behavior in Preschoolers. Pratiques Psychologiques, 22, 61-73.

https://doi.org/10.1016/j.prps.2015.09.004 
[73] Bukowski, H.B. and Samson, D. (2014) Can Emotions Affect Level 1 Visual Perspective-Taking? Cognitive Neuroscience, In Press.

[74] Hutchins, T.L., Prelock, P.A. and Bonazinga, L.A. (2012) Psychometric Evaluation of the Theory of Mind Inventory (ToMI): A Study of Typically Developing Children and Children with Autism Spectrum Disorder. Journal of Autism and Developmental Disorders, 42, 327-341. https://doi.org/10.1007/s10803-011-1244-7

[75] Houssa, M., Mazzone, S. and Nader-Grosbois, N. (2014) Validation d'une version francophone de l'Inventaire de la Théorie de l'Esprit. [Validation of a French Version of the Theory of Mind Inventory.] Revue européenne de psychologie appliquée, 64, 169-179. https://doi.org/10.1016/j.erap.2014.02.002

[76] Catale, C., et al. (2013) French Adaptation of the Childhood Executive Functioning Inventory (CHEXI). European Journal of Psychological Assessment, 29, 149-155. https://doi.org/10.1027/1015-5759/a000141

[77] LaFrenière, P.J. and Dumas, J.E. (1995) Social Competence and Behavior Evaluation, Preschool Edition. Western Psychological Services, Los Angeles.

[78] Hughes, C., et al. (1997) Social Behavior in Pervasive Developmental Disorders: effects of Informant, Group and "Theory of Mind". European Child and Adolescent Psychiatry, 6, 191-198.

[79] Shields, A. and Cicchetti, D. (1997) Emotion Regulation among School-Age Children: The Development and Validation of a New Criterion Q-Sort Scale. Developmental Psychology, 33, 906-916. https://doi.org/10.1037/0012-1649.33.6.906

[80] Nader-Grosbois, N. and Mazzone, S. (2014) Validation de la version francophone de l'Inventaire de Régulation émotionnelle. [Validation of a French Version of the Emotional Regulation Inventory.] Revue Européenne de Psychologie Appliquée.

[81] Carlson, S.M. and Moses, L.J. (2001) Individual Differences in Inhibitory Control and Children's Theory of Mind. Child Development, 74, 1032-1053. https://doi.org/10.1111/1467-8624.00333

[82] Sabbagh, M.A., et al. (2006) The Development of Executive Functioning and Theory of Mind: A Comparison of Chinese and US Preschoolers. Psychological Science, 17, 74-81. https://doi.org/10.1111/j.1467-9280.2005.01667.x

[83] Roskam, I., et al. (2015) Stimulating Parents' Self-Efficacy Beliefs or Verbal Responsiveness: Which Is the Best Way to Decrease Children's Externalizing Behaviors? Behaviour Research and Therapy, 72, 38-48. https://doi.org/10.1016/j.brat.2015.06.012

[84] Webster-Stratton, C. (2000) The Incredible Years Training Series. Juvenile Justice Bulletin. Office of Juvenile Justice and Delinquency Prevention, U.S. Department of Justice, Washington DC. 